\title{
SIMULTANEOUS REMOVAL OF ESTROGENS AND PATHOGENS FROM SECONDARY TREATED WASTEWATER BY SOLAR PHOTOCATALYTIC TREATMENT
}

\author{
FANOURGIAKIS S. ${ }^{1}$ \\ FRONTISTIS Z. ${ }^{2, *}$ \\ CHATZISYMEON E. ${ }^{3}$ \\ VENIERI D. ${ }^{1}$ \\ MANTZAVINOS D. ${ }^{2}$
}

\author{
${ }^{1}$ School of Environmental Engineering, Technical University of Crete \\ Polytechneioupolis, GR-73100 Chania, Greece \\ ${ }^{2}$ Department of Chemical Engineering, University of Patras \\ Caratheodory 1, University Campus, GR-26504 Patras \\ ${ }^{3}$ Institute for Infrastructure and Environment, School of Engineering \\ The University of Edinburgh \\ The King's Buildings, Edinburgh EH9 3JL, United Kingdom
}

*to whom all correspondence should be addressed: e-mail: zaxoys@gmail.com

\section{ABSTRACT}

Recently, the fate of emerging compounds in environmentally relevant samples has attracted considerable attention. Solar semiconductor photocatalysis may offer an appealing methodology to treat such contaminants. At the same time the use of solar photocatalysis for water and wastewater disinfection is a topic well-documented in the literature. In this respect, the simultaneous degradation of synthetic estrogen $17 \alpha$-ethynylestradiol (EE2) and Escherichia coli removal employing simulated solar radiation and $\mathrm{TiO}_{2}$ as the photocatalyst was investigated. In general, the more complex the water matrix is the slower $E$. coli removal becomes, while the presence of $E$. coli in the reaction mixture did not obstruct EE2 removal.

Although EE2 removal occurred relatively fast, overall estrogenic activity was only partially removed. This implies that other species inherently present in the effluent and/or some photocatalytic transformation by-products may be proportionately more estrogenic than EE2. Overall, the use of solar radiation can constitute an advantageous treatment strategy for the simultaneous removal of micropollutants and pathogens from secondary treated effluent.

Keywords: disinfection; E. coli; solar irradiation; photocatalysis; titanium dioxide; estrogens; endocrine disruptors.

\section{Introduction}

Occurrence, impact, and removal of emerging contaminants from water and wastewater have been the target of many studies in the last decades (Michael et al., 2013; Sumpter and Johnson, 2008). Endocrine disrupting compounds (EDCs) constitute an important class of emerging environmental contaminants, which pose an increasing threat to aquatic organisms, as well as to human health (Jjemba, 2008, Belgiorno et al., 2007; Jobling et al., 1998). In particular, the exposure to EDCs has been linked with altering functions of the endocrine system in male fish such as vitellogenin induction and feminized reproductive organs (Belgiorno et al., 2007). Moreover, the increasing incidence of cancer and the hypothesis of a decreasing reproductive fitness of males, are thought to be attributed to EDCs (Auriol et al., 2006). Natural and synthetic estrogen hormones such as $17 \beta$-estradiol, estriol and $17 \alpha-$ ethynylestradiol (EE2) are well-known for their estrogenic activity. These enter municipal wastewater treatment plants (WWTPs) through either excretion or disposal of unused and expired medicines in the

Fanourgiakis S., Frontistis Z., Chatzisymeon E., Venieri D. and Mantzavinos D. (2014), Simultaneous removal of estrogens and pathogens from secondary treated wastewater by solar photocatalytic treatment, Global NEST Journal, 16(3), 543-552. 
sewage system (Kuster et al., 2009). Currently, when EDCs enter sewage system, and afterwards conventional biological WWTP, only a small amount of these chemicals are removed via biodegradation process because many of them are non-biodegradable (Richardson, 2009). Therefore, the majority of EDCs remain soluble in the effluent and been discharged to aquatic bodies (Stasinakis et al., 2008; Vajda et al., 2008; Desbrow et al., 1998). Thus, it is necessary to look further on the removal mechanisms, in order to improve the efficiency of the existing treatment systems and to develop new and reliable treatment strategies to remove EDCs from wastewater (Michael et al., 2013; Klavarioti et al., 2009; Comninellis et al., 2008).

Until now, several authors have demonstrated the efficiency of various physico-chemical processes like adsorption or membrane technology for the elimination of EDCs (Gerrity et al., 2011; Snyder et al., 2007). The main drawback of these techniques is that the emerging contaminants transfers to another phase (adsorption), or the production of a secondary stream with a concentrated solution of EDCs, requiring an additional treatment, such as the membranes-separation technology.

On the contrary several authors reported the efficiency of advanced oxidation processes (AOPs), a group of chemical treatment procedures designed to remove organic (and sometimes inorganic) materials in water and waste water, by oxidation reactions with hydroxyl radicals $(\cdot \mathrm{OH})$. AOPs can eliminate the emerging contaminants in aqueous phase, rather than collecting or transferring pollutants into another phase (Michael et al., 2013; Klavarioti et al., 2009).

In the present study, solar photocatalytic process was applied for this purpose.

Nowadays, photocatalytic processes are also used as an alternative disinfection technology replacing the chlorination step that is widely used in WWTPs (Rizzo et al., 2014; Malato et al., 2009; Melemeni et al., 2009). It is well-known that when chlorine is used as a disinfectant, it reacts with the natural organic matter present in water and wastewater to produce various undesirable chlorinated disinfection byproducts (DBPs) (Hua and Reckhow, 2007). Of the wide variety of chlorinated DBPs formed, trihalomethanes and haloacetic acids are of primary concern since many of them have been found to be carcinogenic and/or mutagenic (Richardson, 2003). Therefore, ongoing research focuses on the development of alternative disinfection methods (Lazarova et al., 1999). It is worth noting that usually the application of advanced oxidation processes is limited by their high cost. However, according to Vidal et al., (1999), the estimated total costs for solar photocatalytic degradation of $500 \mathrm{\mu g} \mathrm{I}^{-1}$ of selected pesticides to maximum permitted levels $\left(0.1 \mu \mathrm{g} \mathrm{I}^{-1}\right)$ and the four-log inactivation of $\mathrm{E}$. faecalis bacteria, is competitive with conventional technologies and estimated to be about US\$0.7 per $\mathrm{m}^{3}$.

In recent years, various studies have been conducted to demonstrate photocatalytic disinfection under visible light, using mostly $E$. coli as a model microorganism, which is the well known bacterial indicator of faecal pollution (Rizzo et al., 2014; Suri et al., 2012; Chatzisymeon et al., 2011; Dalrymple et al., 2010; Gamage and Zhang, 2010; McCullagh et al., 2007), however, the majority of studies focus strictly on the removal of $E$. coli without considering the presence of other emerging contaminants. Hence, this work reports the efficacy of solar $\mathrm{TiO}_{2}$-mediated photocatalytic process to remove simultaneously $\mathrm{EE} 2$ and $E$. coli from secondary treated wastewaters.

\section{Materials and Methods}

\subsection{Materials}

EE2 $\left(\mathrm{C}_{20} \mathrm{H}_{24} \mathrm{O}_{2}\right)$, whose main physicochemical properties are given in Table 1, was purchased from SigmaAldrich (CAS number: 57-63-6) and used as received. Aeroxide P25 titania (formerly known as Degussa P25, 75:25 anatase:rutile, $50 \mathrm{~m}^{2} \mathrm{~g}^{-1}$ BET area, $21 \mathrm{~nm}$ particle size, supplied by Evonik Industries) was employed as the photocatalyst. The bacterial reference strain used in this study was E. coli ATCC 23716 (American Type Culture Collection, Rockville, MD, USA). Colonies of the reference strain were inoculated in sterile distilled water, which was used as sample for synthetic wastewater disinfection experiments. The concentration of bacterial cells in the suspension was estimated measuring its optical density at 600 $\mathrm{nm}$ (Shimadzu UV1240 spectrophotometer) where, according to McFarland scale, an absorbance of 0.132 corresponds approximately to a cell density of $1.510^{8} \mathrm{CFU} \mathrm{ml}{ }^{-1}$. Plate counts were also performed 
for accurate bacterial count. The concentration of the inocula was within the range of $10^{3}-10^{7} \mathrm{CFU} \mathrm{ml}{ }^{-1}$, depending on the experiment conducted.

Table 1. Properties of $17 \alpha$-ethynylestradiol

\begin{tabular}{lc}
\hline Compound & 17 $\alpha$-Ethynylestradiol (EE2) \\
\hline IUPAC name & 17 $\alpha$-Ethynyl-1,3,5(10)-estratriene-3,17 $\beta$-diol \\
\hline CAS number & $57-63-6$ \\
\hline Molecular formula & $\mathrm{C}_{20} \mathrm{H}_{24} \mathrm{O}_{2}$ \\
\hline Molar mass, $\mathrm{g} \mathrm{mol}^{-1}$ & 296.40 \\
\hline Appearance & White crystalline powder \\
\hline Melting point, ${ }^{\circ} \mathrm{C}$ & $182-183$ \\
\hline${ }^{*}$ Solubility in water, $\mathrm{mg} \mathrm{l}^{-1}$ & $9.2 \pm 0.09$ \\
\hline
\end{tabular}

*Data taken from (Shareef et al., 2006)

Wastewater (WW) collected from the outlet of the secondary treatment of a municipal WWTP (Chania, W. Crete, Greece). The matrix was characterized by standard methods as follows: the chemical oxygen demand (COD) and dissolved organic carbon (DOC) was 24 and $8.4 \mathrm{mg} \mathrm{I}^{-1}$, respectively, while its $\mathrm{pH}$ was about 8 and the conductivity $820 \mu \mathrm{S} \mathrm{cm}^{-1}$. Moreover, it contained $172 \mathrm{mg} \mathrm{l}^{-1}$ chlorides, $194 \mathrm{mg} \mathrm{I}^{1}$ bicarbonates, $54 \mathrm{mg} \mathrm{I}^{-1}$ sulfates, $37 \mathrm{mg} \mathrm{I}^{-1}$ nitrates and $37 \mathrm{mg} \mathrm{I}^{-1}$ nitrites.

\subsection{Photocatalytic experiments}

Simulated solar radiation experiments took place in a batch-type, laboratory-scale photoreactor. The volume of the reactant mixture was $300 \mathrm{ml}$. Radiation was provided by a Newport $67005-150 \mathrm{~W}$ solar simulator system. Chemical actinometry based on 2-nitrobenzaldehyde photoreaction (Galbavy et al., 2010) was performed to measure the photon flux emitted from the solar simulator system which was found equal to $5.8 \times 10^{-7}$ einstein $\left.I^{-1} \mathrm{~s}^{-1}\right)$. In a typical photocatalytic run, the effluent was loaded in the reaction vessel and the solution was slurried with the proper amount of $\mathrm{TiO}_{2}$. The resulting $\mathrm{TiO}_{2}$ suspension was magnetically stirred for $30 \mathrm{~min}$ in the dark to ensure complete equilibration of adsorption/desorption of EE2 and E. coli onto the catalyst surface. At specific time intervals, samples of about 2-3 $\mathrm{ml}$ were drawn from the reaction vessel and were centrifuged at $13200 \mathrm{rpm}$ to remove catalyst particles and then analyzed for residual estrogens concentration. E. coli survival was also estimated for the same samples before undergoing any centrifugation process.

\subsection{Analytical and molecular biology techniques}

High performance liquid chromatography (Alliance 2690, Waters) was employed to monitor the concentration of EE2. Separation was achieved on a Luna C-18(2) column $(5 \mu \mathrm{m}, 250 \mathrm{~mm} \times 4.6 \mathrm{~mm})$ and a security guard column $(4 \mathrm{~mm} \times 3 \mathrm{~mm})$, both purchased from Phenomenex. The mobile phase consisting of 35 : 65 ultrapure water: acetonitrile eluted isocratically at $1 \mathrm{ml} \mathrm{min}^{-1}$ and $30{ }^{\circ} \mathrm{C}$, while the injection volume was $100 \mu \mathrm{l}$. Detection was achieved through a fluorescence detector (Waters 474 Scanning Fluorescence detector), in which the excitation wavelength was $280 \mathrm{~nm}$ and the emission wavelength was $305 \mathrm{~nm}$. Under these conditions, the retention time was $5.1 \mathrm{~min}$, the limit of detection (LOD) was $0.63 \mu \mathrm{gl}^{-1}$ and the limit of quantitation (LOQ) was $2.11 \mu \mathrm{gl}^{-1}$ (Frontistis et al., 2012a).

The detection and enumeration of $E$. coli in the reaction solution were performed using the serial dilution streak plate agar technique. Serial dilutions of the reaction solution were performed in sterile $0.8 \%(\mathrm{w} / \mathrm{v} \%) \mathrm{NaCl}$ aqueous solution and $200 \mu \mathrm{l}$ of each dilution (including neat sample) were streaked onto HiCrome Coliform Agar plates (HiMedia Laboratories), which is a selective E. coli culture medium. The plates were incubated at $37^{\circ} \mathrm{C}$ for $20-24 \mathrm{~h}$ before viable counts were determined. The minimum detectable number of bacteria in these experiments was $1 \mathrm{CFU} \mathrm{m}{ }^{-1}$ (a reflection of the fact that $1000 \mu \mathrm{L}$ of neat sample $(5 \times 200 \mu \mathrm{l})$ were cultured out from each neat sample) (Venieri et al., 2014).

Genomic DNA was extracted performing chemical lysis and phenol/chloroform/isoamyl alcohol (25:24:1) extraction using lysozyme and proteinase K, according to our previous work (Venieri et al., 2013). The 
quantity and purity of all DNA samples were determined measuring their absorbance at $260 \mathrm{~nm}$ and estimating the ratio of absorbance values at $260 \mathrm{~nm}$ and $280 \mathrm{~nm}$, respectively.

The SYBR green qPCR method was chosen for the detection and quantification of gadAB gene of residual E. coli cells after each photocatalytic experiment using the StepOne Plus System (Applied Biosystems Inc., Foster City, CA, USA). The gadAB gene encodes glutamate decarboxylase and has both sensitivity and specificity to $E$. coli. The primers for the target gene were as follows: forward primer $5^{\prime}$-GCG TTG CGT AAA TAT GGT TGC CGA-3' (gadrt-1) and reverse primer 5'-CGT CAC AGG CTT CAA TCA TGC GTT-3' (gadrt-2) (Chen et al., 2006). The product size for this primer set is $305 \mathrm{bp}$. Triplicate PCR reactions were carried out with Quantimix Easy SYG Kit (Biotools) to a final volume of $20 \mu \mathrm{L}$. The mixed qPCR solution contained 2XPCR master mix, $0.5 \mathrm{mM}$ of each primer, $30 \mathrm{nM}$ of reference dye (Rox) all diluted to the final volume of the reaction mixture with DNase/RNase free water. PCR reactions were carried out at a temperature profile of $10 \mathrm{~min}$ initial denaturation at $95^{\circ} \mathrm{C}$, followed by 40 cycles each of denaturation at $95{ }^{\circ} \mathrm{C}$ for $0.5 \mathrm{~min}$, annealing at $57^{\circ} \mathrm{C}$ for $1 \mathrm{~min}$, and extension at $72{ }^{\circ} \mathrm{C}$ for $0.5 \mathrm{~min}$. Deionized water and DNase-treated $E$. coli served as negative controls. Melting curve analyses were conducted from 55 to $95^{\circ} \mathrm{C}\left(1{ }^{\circ} \mathrm{C}\right.$ per cycle of $10 \mathrm{~s}$ ) with simultaneous measurements of the SYBR Green signal intensities.

The yeast estrogen screening (YES) test was employed to evaluate overall estrogenicity according to the procedures described elsewhere (Frontistis et al., 2011a).

\section{Results and discussion}

\subsection{Effect of catalyst concentration}

The effect of catalyst loading in the range $250-1500 \mathrm{mg} \mathrm{l}^{-1}$ on the photocatalytic disinfection in the presence of $100 \mathrm{mg} \mathrm{I}^{-1} \mathrm{EE} 2$ was investigated and the results are shown in Figure 1.

As can be seen, increasing catalyst loading up to $750 \mathrm{mg} \mathrm{l}^{-1}$, photocatalytic efficiency increased in terms of both EE2 and E. coli removal. The increase in the efficiency with increasing catalyst loading indicates a heterogeneous catalytic regime, since the fraction of incident light absorbed by the catalyst progressively increases in suspensions containing higher amounts of titanium dioxide (Herrmann, 2010). Increasing catalyst loading apparently results in an increased number of catalyst active sites that are available for photocatalytic reactions and this occurs up to a point where all catalyst particles become fully illuminated (Poulios and Kyriacou, 2002).

\subsection{Effect of wastewater matrix}

The organic and inorganic species typically found in environmentally relevant matrices may interfere with the oxidizing agents (e.g. photogenerated holes, as well as hydroxyl radicals) and affect the rate of disinfection. This is evident in Figure 2 showing that the matrix has an adverse effect on conversion and/or reaction rate; for instance, after $90 \mathrm{~min}$ of treatment at $500 \mathrm{mg} \mathrm{I}^{-1}$ titania disinfection efficiency for real wastewater was 3 times less than the respective value for the synthetic effluent (initial bacterial concentration $1 \times 10^{3} \mathrm{CFU} \mathrm{ml}{ }^{-1}$ ). This behaviour has been observed several times from our group in the degradation of organic compounds by heterogeneous photocatalysis (Frontistis et al., 2012a, Frontistis et al., 2012b) and photocatalytic disinfection (Chatzisymeon et al., 2011).

This can be explained taking into account that (i) the oxidizing agents are competitively consumed in reactions involving the natural organic matter present in treated WW but not in pure water and constitutes most of the matrix's total organic content; (ii) hydroxyl radicals may be scavenged by bicarbonates, chlorides and sulfates present in WW to form the respective radicals, whose oxidation potential is lower than that of hydroxyl radicals (Frontistis et al., 2012a) 


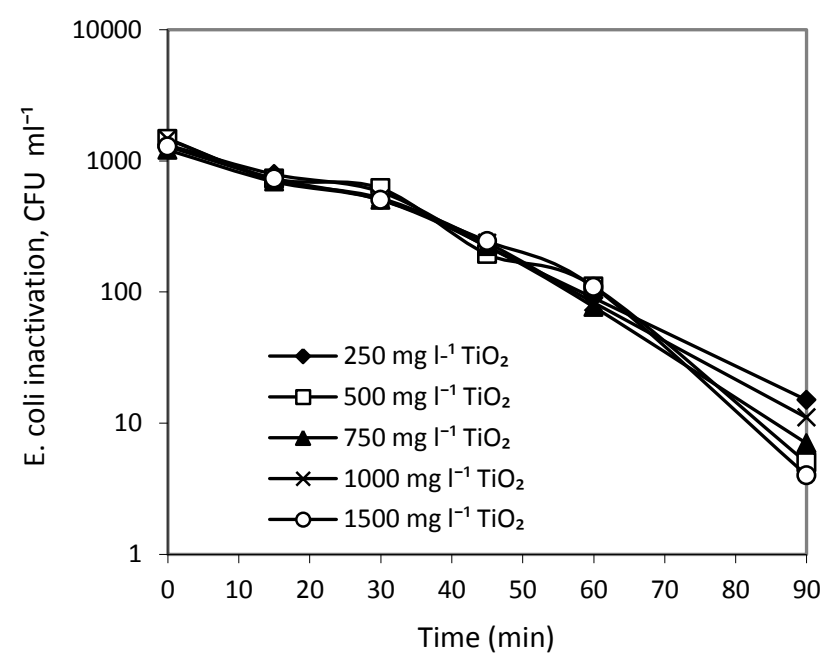

(a)

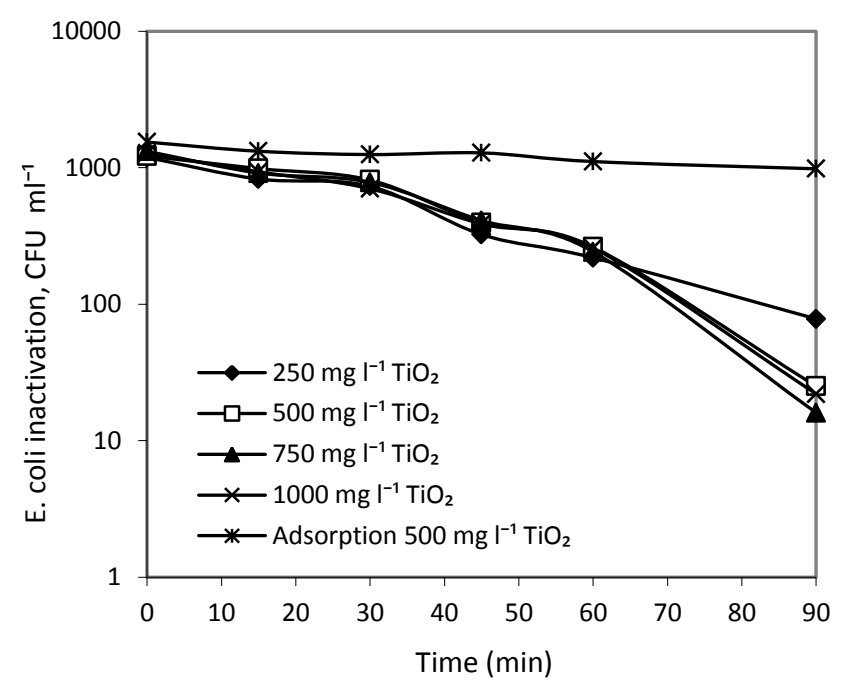

(b)

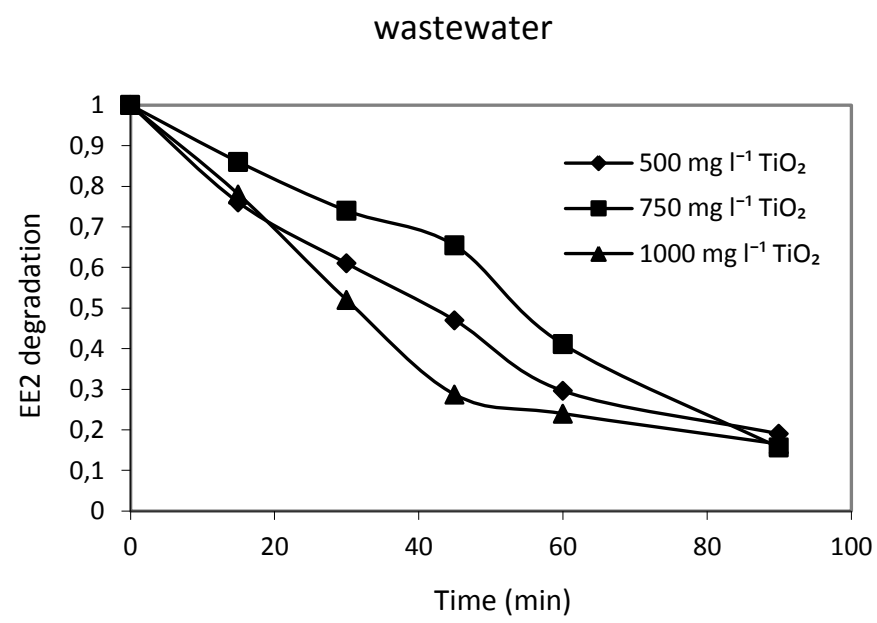

(c)

Figure 1. Effect of catalyst loading on photocatalytic performance.

(a) E. coli in synthetic wastewater; (b) E. coli in actual wastewater; (c) EE2 in actual wastewater 


\subsection{EE2 \& E. coli interaction}

Experiments were carried out to investigate the possible interactions of EE2 with E. coli. Figure 2 clearly demonstrates that the influence of the presence of $E$. coli is almost negligible to EE2 removal. Particularly, EE2 removal in synthetic wastewater came up to $84.5 \%$ and $89.9 \%$, after 90 min of treatment, under simulated solar irradiation, in the presence or absence of $E$. coli, respectively.

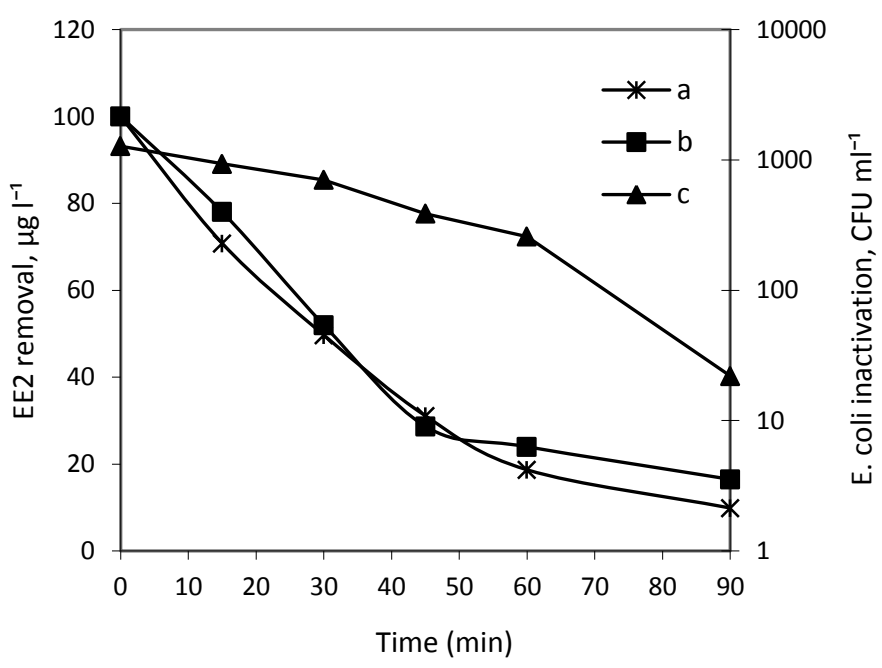

Figure 2. Photocatalytic efficiency under solar radiation with $1000 \mathrm{mg} \mathrm{I}^{-1}$ titania. (a) EE2 removal from a synthetic wastewater matrix inoculated with $100 \mathrm{\mu g} \mathrm{I}^{-1} \mathrm{EE2}$, (b) EE2 removal from a synthetic wastewater matrix inoculated with $100 \mathrm{\mu g} \mathrm{I}^{-1} \mathrm{EE} 2$ and $10^{3} \mathrm{CFU} \mathrm{ml^{-1 }}$ E. coli, and (c) E. coli inactivation from

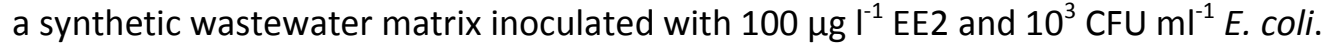

However, the presence of estrogens has been associated with an increase in the risk of mutagenicity and genotoxicity. According to Roy and Liehr, (1999) various types of estrogen-induced DNA damage include: (a) direct covalent binding of estrogen quinone metabolites to DNA; (b) enhancement of endogenous DNA adducts by chronic estrogen exposure of rodents; (c) free radical generation by metabolic redox cycling between quinone and hydroquinone forms of estrogens and free radical damage to DNA. These types of DNA damage (i.e., 8-hydroxydeoxyguanine, lipid-DNA adducts and DNA strand breaks) generated by estrogen treatment or reactive metabolites of estrogens, are all potentially significant, because these lesions are capable of producing changes in the genome.

In an attempt to evaluate the consistency and integrity of microbial DNA in our wastewater samples, qPCR was performed for the detection and quantification of $E$. coli gadAB gene, isolated from residual viable cells after each photocatalytic experiment. The presence of EE2 and its photodegradation byproducts may lead to $E$. coli genomic extensive DNA damage, which subsequently may inhibit any generation of PCR products. In our case SYBR green qPCR proved to be effective in the detection and quantification of bacterial DNA during photocatalytic experiments, as there was successful generation of gadAB gene product of $305 \mathrm{bp}$. In the present study, the high size/length of PCR product and the postamplification melting curve analysis ensured the specificity and reliability of the method. Melting curve analysis is an assessment of the dissociation-characteristics of double-stranded DNA during heating. As the temperature is raised, the double strand begins to dissociate leading to a rise in the absorbance intensity, hyperchromicity. The temperature at which $50 \%$ of DNA is denatured is known as the melting point. The information gathered can be used to infer the presence and identity of possible polymorphisms with further analysis. 


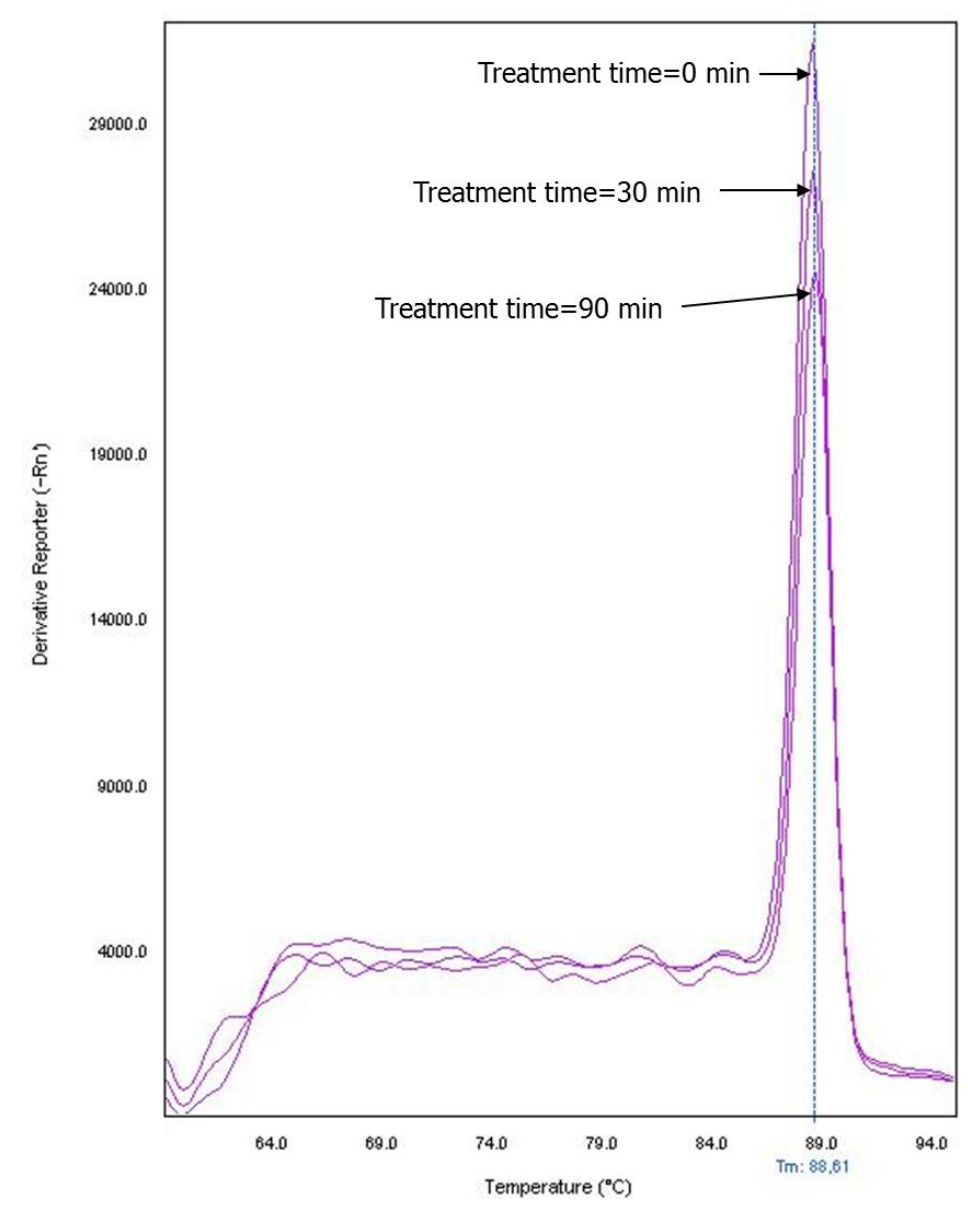

Figure 3. Melting curves in real-time for synthetic wastewater samples during their $90 \mathrm{~min}$ photocatalytic treatment, in the presence of $100 \mathrm{\mu g}^{-1} \mathrm{EE} 2$

As shown in Figure 3, the point of infection (melting temperature of the amplicon) occurs at $88.6^{\circ} \mathrm{C}$ and remains stable during photocatalytic treatment, showing that there are no considerable alterations to the bacterial DNA or PCR byproducts. Also, it is shown that DNA quantity is substantially decreased during the 90 min photocatalytic treatment and this is consistent with the decrease of bacteria survival, which was quantified by the serial dilution culture technique (Figure 2). In addition, it can be seen that no contaminating products are present in this PCR reaction, since contaminated DNA or primer dimers would show up as an additional peak separate from the desired melt curve amplicon peak. Consequently, it is interesting to note that there are no extensive DNA alterations, at least within the studied gene during the 90 min photocatalytic treatment of $E$. coli in the presence of EE2 in synthetic wastewater.

\subsection{Removal of estrogen activity}

Figure 4 shows changes in effluent's overall estrogen activity (as assessed by the YES assay) during 100

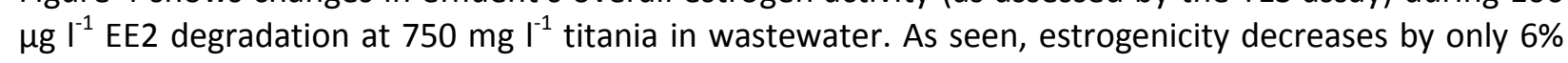
after 30 min of reaction and this coincides with $30 \%$ EE2 removal. Estrogen activity slightly increases and then drops again leading to a final (i.e. after $90 \mathrm{~min}$ ) reduction of $14 \%$; these findings imply that certain EE2 and/or effluent organic matter transformation byproducts are proportionately more estrogenic than the parent compounds. Similar behaviour has been reported in recent studies from our group dealing with EE2 and estrogenicity removal by ultrasound irradiation and electrochemical oxidation (Frontistis et al., 2011b, Frontistis and Mantzavinos, 2012). 


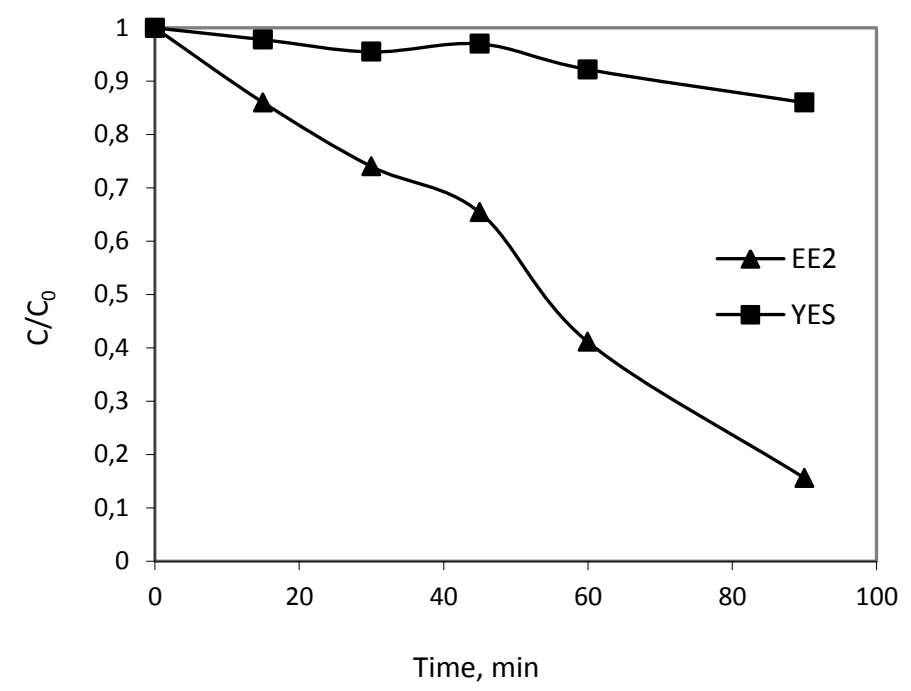

Figure 4. EE2 and estrogenicity removal during photocatalytic treatment of actual wastewater with $750 \mathrm{mg} \mathrm{I}^{-1}$ titania

These results show the need for further research on the correlation of the change in estrogenicity and EE2 in real aqueous matrices in order to assess the influence of the transformation byproducts of natural organic matter on estrogen activity.

At the same time, the effluent's dissolved organic carbon remains practical unchanged, thus indicating insignificant mineralization to carbon dioxide.

\section{Conclusions}

In this study, $\mathrm{TiO}_{2}$-mediated solar photocatalytic treatment was successfully applied for the simultaneous removal of estrogens and pathogens from secondary treated effluent. Hence, the main conclusions drawn from this study are summarized as follows:

1) The more complex the water matrix is the slower the disinfection rate becomes; this is due to the non-target species inherently present in the matrix behaving as scavengers of the photogenerated oxidants. Nevertheless, the presence of $E$. coli in the reaction mixture did not obstruct EE2 removal.

2) The generation and quantification of E. coli gadAB gene during the photocatalytic treatment in the presence of EE2 in synthetic wastewater was successful through qPCR. Melting curve analysis showed no significant alterations in the specific gene segment or the formation of any byproducts.

3) Although EE2 removal occurred relatively fast, overall estrogenic activity was only partially removed. This implies that other species inherently present in the effluent and/or some photocatalytic transformation byproducts may be proportionately more estrogenic than EE2.

\section{Acknowledgements}

The authors wish to thank Dr E. Routledge (Brunel University, UK) for supplying yeasts for the YES test.

\section{References}

Auriol M., Filali-Meknassi Y., Tyagi R.D., Adams C.D. and Surampalli R.Y. (2006), Endocrine disrupting compounds removal from wastewater, a new challenge, Process Biochemistry, 41, 525-539. 
Belgiorno V., Rizzo L., Fatta D., Della Rocca C., Lofrano G., Nikolaou A., Naddeo V. and Meric S. (2007), Review on endocrine disrupting-emerging compounds in urban wastewater: occurrence and removal by photocatalysis and ultrasonic irradiation for wastewater reuse, Desalination, 215, 166-176.

Chatzisymeon E., Droumpali A., Mantzavinos D. and Venieri D. (2011), Disinfection of water and wastewater by UVA and UV-C irradiation: application of real-time PCR method, Photochemical \& Photobiological Sciences, 10, 389-395

Chen Y.C., Higgins M.J., Maas N.A. and Murthy S.N. (2006), DNA extraction and Escherichia coli quantification of anaerobically digested biosolids using the competitive touchdown PCR method, Water Research, 40, 3037-3044.

Comninellis C., Kapalka A., Malato S., Parsons S.A., Poulios I. and Mantzavinos D. (2008), Advanced oxidation processes for water treatment: advances and trends for R\&D, Journal of Chemical Technology and Biotechnology, 83, 769-776.

Dalrymple O.K., Stefanakos E., Trotz M.A. and Goswami D.Y. (2010), A review of the mechanisms and modeling of photocatalytic disinfection, Applied Catalysis B: Environmental, 98, 27-38.

Desbrow C.E. J.R., Routledge E.J., Brighty G.C., Sumpter J.P. and Waldock M. (1998), Identification of estrogenic chemicals in STW effluent. 1. Chemical fractionation and in vitro biological screening, Environmental Science \& Technology, 32, 1549-1558.

Frontistis Z. and Mantzavinos D. (2012), Sonodegradation of $17 \alpha$-ethynylestradiol in environmentally relevant matrices: Laboratory-scale kinetic studies, Ultrasonics sonochemistry, 19, 77-84.

Frontistis Z., Brebou C., Venieri D., Mantzavinos D. and Katsaounis A. (2011b), BDD anodic oxidation as tertiary wastewater treatment for the removal of emerging micro-pollutants, pathogens and organic matter, Journal of Chemical Technology and Biotechnology, 86, 1233-1236.

Frontistis Z., Daskalaki V.M., Hapeshi E., Drosou C., Fatta-Kassinos D., Xekoukoulotakis N.P. and Mantzavinos D. (2012b), Photocatalytic (UV-A/TiO $)$ degradation of $17 \alpha$-ethynylestradiol in environmental matrices: Experimental studies and artificial neural network modeling, Journal of Photochemistry and Photobiology A: Chemistry, 240, 33-41.

Frontistis Z., Drosou C., Tyrovola K., Mantzavinos D., Fatta-Kassinos D., Venieri D. and Xekoukoulotakis N.P. (2012a), Experimental and modeling studies of the degradation of estrogen hormones in aqueous $\mathrm{TiO}_{2}$ suspensions under simulated solar radiation, Industrial \& Engineering Chemistry Research, 51, 16552-16563.

Frontistis Z., Xekoukoulotakis N.P., Hapeshi E., Venieri D., Fatta-Kassinos D. and Mantzavinos D. (2011a), Fast degradation of estrogen hormones in environmental matrices by photo-Fenton oxidation under simulated solar radiation, Chemical Engineering Journal, 178, 175-182.

Galbavy E.S., Ram K. and Anastasio C. (2010), 2-Nitrobenzaldehyde as a chemical actinometer for solution and ice photochemistry, Journal of Photochemistry and Photobiology A: Chemistry, 209, 186-192.

Gamage J. and Zhang Z. (2010), Applications of Photocatalytic Disinfection, International Journal of Photoenergy, Article ID 764870, doi:10.1155/2010/764870.

Gerrity D., Gamage S., Holady J.C., Mawhinney D.B., Quinones O., Trenholm R.A. and Snyder S.A. (2011), Pilot-scale evaluation of ozone and biological activated carbon for trace organic contaminant mitigation and disinfection, Water research, 45, 2155-2165.

Herrmann J.M. (2010), Photocatalysis fundamentals revisited to avoid several misconceptions, Applied Catalysis B: Environmental, 99, 461-468.

Hua G. and Reckhow D.A. (2007), Comparison of disinfection byproduct formation from chlorine and alternative disinfectants, Water Research, 41, 1667-1678.

Jjemba P. K. (2008), Index in Pharma-Ecology: The Occurrence and Fate of Pharmaceuticals and Personal Care Products in the Environment, John Wiley \& Sons, Inc., Hoboken, NJ, USA.

Jobling S., Nolan M., Tyler C.R., Brighty G. and Sumpter J.P. (1998), Widespread sexual disruption in wild fish, Environmental science \& technology, 32, 2498-2506.

Klavarioti M., Mantzavinos D. and Kassinos D. (2009), Removal of residual pharmaceuticals from aqueous systems by advanced oxidation processes, Environment International, 35, 402-417.

Kuster M., Azevedo D.D.A., López de Alda M.J., Aquino Neto F.R. and Barceló D. (2009), Analysis of phytoestrogens, progestogens and estrogens in environmental waters from Rio de Janeiro (Brazil), Environment International, 
35, 997-1003.

Lazarova V., Savoye P., Janex M.L., Blatchley III E. R. and Pommepuy M. (1999), Advanced wastewater disinfection technologies: state of the art and perspectives, Water Science and Technology, 40, 203-213.

Malato S., Fernández-Ibáñez P., Maldonado M.I., Blanco J. and Gernjak W. (2009), Decontamination and disinfection of water by solar photocatalysis: recent overview and trends, Catalysis Today, 147, 1-59.

McCullagh C., Robertson J.M., Bahnemann D.W. and Robertson P.K. (2007), The application of $\mathrm{TiO}_{2}$ photocatalysis for disinfection of water contaminated with pathogenic micro-organisms: a review, Research on Chemical Intermediates, 33, 359-375.

Melemeni M., Stamatakis D., Xekoukoulotakis N.P., Mantzavinos D. and Kalogerakis N. (2009), Disinfection of municipal wastewater by $\mathrm{TiO}_{2}$ photocatalysis with UV-A, visible and solar irradiation and BDD electrolysis, Global NEST Journal, 11, 357-363.

Michael I., Frontistis Z. and Fatta-Kassinos D. (2013), Removal of pharmaceuticals from environmentally relevant matrices by advanced oxidation processes (AOPs), Comprehensive Analytical Chemistry, 62, 345-407.

Poulios I. and Kyriacou G. (2002), Photocatalytic degradation of p-coumaric acid over $\mathrm{TiO}_{2}$ suspensions, Environmental Technology, 23, 179-187.

Richardson S.D. (2003), Disinfection by-products and other emerging contaminants in drinking water, TrAC Trends in Analytical Chemistry, 22, 666-684.

Richardson S.D. (2009), Water analysis: emerging contaminants and current issues, Analytical Chemistry, 81, 4645-4677.

Rizzo L., Della Sala A., Fiorentino A. and Li Puma G. (2014), Disinfection of urban wastewater by solar driven and UV lamp- $-\mathrm{TiO}_{2}$ photocatalysis: Effect on a multi drug resistant $E$. coli strain, Water Research, 53, 145-152

Rizzo L., Ferro G. and Manaia C.M. (2014), Wastewater disinfection by solar heterogeneous photocatalysis: effect on tetracycline resistant/sensitive Enterococcus strains, Global NEST Journal, In Press, Available online 18/02/2014.

Roy D. and Liehr J.G. (1999), Estrogen, DNA damage and mutations. Mutation Research/Fundamental and Molecular Mechanisms of Mutagenesis, 424, 107-115.

Shareef A., Angove M.J., Wells J.D. and Johnson B.B. (2006), Aqueous solubilities of estrone, 17 $\beta$-estradiol, $17 \alpha$ ethynylestradiol, and bisphenol A, Journal of Chemical \& Engineering Data, 51, 879-881.

Snyder S.A., Adham S., Redding A.M., Cannon F.S., DeCarolis J., Oppenheimer J., Wert E.C. and Yoon Y. (2007), Role of membranes and activated carbon in the removal of endocrine disruptors and pharmaceuticals, Desalination, 202, 156-181.

Stasinakis A.S., Gatidou G., Mamais D., Thomaidis N.S. and Lekkas T.D. (2008), Occurrence and fate of endocrine disrupters in Greek sewage treatment plants, Water Research, 42, 1796-1804.

Sumpter J.P. and Johnson A.C. (2008), 10th Anniversary Perspective: Reflections on endocrine disruption in the aquatic environment: from known knowns to unknown unknowns (and many things in between), Journal of Environmental Monitoring, 10, 1476-1485.

Suri R.P., Thornton H.M. and Muruganandham M. (2012), Disinfection of water using Pt-and Ag-doped $\mathrm{TiO}_{2}$ photocatalysts, Environmental technology, 33, 1651-1659.

Vajda A.M., Barber L.B., Gray J.L., Lopez E.M., Woodling J.D. and Norris D.O. (2008), Reproductive disruption in fish downstream from an estrogenic wastewater effluent, Environmental science \& technology, 42, 3407-3414.

Venieri D., Chatzisymeon E., Politi E., Sofianos S.S., Katsaounis A. and Mantzavinos D. (2013), Photoelectrocatalytic disinfection of water and wastewater: performance evaluation by qPCR and culture techniques, Journal of Water and Health, 11, 21-29.

Venieri D., Fraggedaki A., Kostadima M., Chatzisymeon E., Binas V., Zachopoulos A., Kiriakidis G. and Mantzavinos D. (2014), Solar light and metal-doped $\mathrm{TiO}_{2}$ to eliminate water-transmitted bacterial pathogens: Photocatalyst characterization and disinfection performance, Applied Catalysis B: Environmental, 154, 93-101.

Vidal A., Diaz A.I., El Hraiki A., Romero M., Muguruza I., Senhaji F. and Gonzalez J. (1999), Solar photocatalysis for detoxification and disinfection of contaminated water: pilot plant studies. Catalysis Today, 54, 283-290. 